\title{
A Study on the Secondary Vocational Students' Intention of Enter to Higher Education in the Underdeveloped Areas of Western China Based on the Theory of Planned Behavior
}

\author{
Xiu Wang, Xuejun Liu, Liman Pang* \\ School of Education Science, Nanjing Normal University, Nanjing, China \\ Email: ${ }^{\star} 190602089 @$ njnu.edu.cn
}

How to cite this paper: Wang, X., Liu, X. J., \& Pang, L. M. (2021). A Study on the Secondary Vocational Students' Intention of Enter to Higher Education in the Underdeveloped Areas of Western China Based on the Theory of Planned Behavior. Chinese Studies, 10, 195-210.

https://doi.org/10.4236/chnstd.2021.104013

Received: October 15, 2021

Accepted: November 16, 2021

Published: November 19, 2021

Copyright $\odot 2021$ by author(s) and Scientific Research Publishing Inc. This work is licensed under the Creative Commons Attribution International License (CC BY 4.0).

http://creativecommons.org/licenses/by/4.0/

\begin{abstract}
Secondary vocational students are the participants of the connection between secondary vocational education and higher education. Their intention of entering higher school determines whether China can smoothly promote the cultivation of high-quality technical talents. Because the proportion of secondary vocational education going to higher school in the underdeveloped areas of western China is relatively low. Therefore, this study is based on the theory of planned behavior to explore the factors that influence the intention of secondary vocational students in underdeveloped areas in western China. Through the questionnaire survey, it is found that there are significant differences in the students' intention of enter to higher education in terms of gender, grade, and academic performance. Students' attitude toward entering higher education, subjective norm, and perceived behavioral control can predict their intention of entering higher education. But in the end, only the attitude toward entering higher education and the perceived behavioral control are included in the regression equation. Finally, based on the results of this research, four suggestions are put forward.
\end{abstract}

\section{Keywords}

Intention of Entering Higher School, Secondary Vocational Students, Theory of Planned Behavior

\section{Introduction}

In 2015, China proposed the "Made in China 2025" strategy (also known as the Chinese version of the "Industry 4.0 Plan"). The strategy clearly requires the ad- 
vancement of the in-depth integration of informatization and industrialization, taking smart manufacturing as the main direction, launching smart manufacturing projects, and promoting the deepening application of the Internet in the manufacturing sector (Shi \& Hao, 2017). In the process of moving toward China's Industry 4.0, due to the adjustment of the industrial structure and the upgrading of enterprise production technology, the demand for new-type skilled talents with high-level technical and skilled personnel has increased (Chen \& Zhang, 2017). As vocational education is the main mode for cultivating applied technical talents in China, the development of vocational education is an important driving force for China to move towards "Industry 4.0". Therefore, increasing the opening up of China's vocational education system and enlarging secondary vocational education students' enrollment scale is to meet the development needs of the times.

At present, our country has entered a new stage of development, and the problem of unbalanced regional development has become the main factor restricting our country from achieving the goal of a modern socialist country. Under the strategic goal of Made in China 2025, the transformation and upgrading of vocational education will inevitably not only rely on the development of local areas. Only by complementing the shortcomings of education development in underdeveloped areas can it be realized to help China's industrialization 4.0. Underdeveloped regions are a concept created by comparison with developed regions. They refer to regions with low economic aggregates, low per capita income, and insufficient accumulation and construction capabilities. China's underdeveloped regions are mainly concentrated in the central and western regions (Liu, 2021). Chinese researchers have constructed a "comprehensive development index" that includes three types of indicators: economic development, social development, environment and environmental development, to evaluate the comprehensive development of China's underdeveloped regions. The results show that Guangxi (0.1566), Yunnan (0.1455), Guizhou (0.1151) and other underdeveloped western regions, the comprehensive development index is far lower than Shanghai (0.8585), or even less than $75 \%$ of the national average (Lin et al., 2007). The difference in the comprehensive development index of various regions in China is also reflected in the serious imbalance of vocational education resources in various regions, and the low quality of vocational education and teaching in the central and western regions. From the average cost of students in secondary vocational schools, teacher-student ratio, teacher education, and teaching equipment, the teaching conditions in the central and western regions are far lower than those in the eastern region, especially the underdeveloped regions in the western region are the least developed (Wang, 2010).

Looking at the progress of secondary vocational education in China, the proportion of secondary vocational students in the eastern developed provinces is as high as $70 \%$. However, the proportion of secondary vocational education in the western underdeveloped areas still has a significant gap compared with the east- 
ern areas. For example, in 2017-2019, the proportion of the number of secondary vocational students entering higher education to the total number of employment in Guangxi Zhuang Autonomous Region was 29.23\%, 32.74\%, and 44.17\%, respectively. From the perspective of the proportion of entering schools over the years, although the proportion of secondary vocational students in the region has been increasing year by year, this value is still far from the proportion of entering schools in the eastern developed regions. Even taking into account the differences in the level of human capital demand for industrial development in different regions. This proportion still reflects to a certain extent the real problem of the low proportion of secondary vocational education students entering schools and the lagging development of vocational education in underdeveloped areas in western China (Shi \& Liang, 2018).

From the perspective of vocational education, increasing the promotion rate of secondary vocational school students will promote the transformation and upgrading of vocational and technical talents in underdeveloped areas in western China, and improve the quality of vocational talents, thereby promoting the coordinated development of vocational education in the eastern and western regions. Secondary vocational students, as a potential student group of the source of higher education, their intention to participate in the advancement of higher education is also an important factor that affects whether the secondary vocational education can be smoothly connected with the upper level school ( $\mathrm{Li} \& \mathrm{Gu}$, 2017). Therefore, it is necessary for us to understand the intention of entering a higher school and its influencing factors in the underdeveloped areas of western China of secondary vocational schools, and to explore the internal and external factors of the low proportion of secondary vocational students in the region. In this way, we can provide more targeted advice and suggestions to schools, teachers, and parents in helping students enter higher education, so as to increase the rate of entering secondary vocational schools and speed up the transformation and upgrading of technically skilled talents in underdeveloped areas in the west.

\section{Theoretical Background}

The Theory of Planned Behavior (TPB) is developed on the basis of the Theory of Reasoned Action (TRA) (Armitage \& Conner, 2001). The theory contains four basic elements: attitude toward the behavior, subjective norm, perceived behavioral control, and intention. The purpose is to analyze the intention to affect individual behavior and predict the probability of behavior. Ajzen (1991) believes that an individual's behavior intention is determined by three variables: attitude toward the behavior, subjective norm, and perceived behavioral control (as shown in Figure 1). If the attitude toward the behavior held by the individual is more positive, the support of important others or groups to the individual behavior is higher, the individual's perceived behavioral control is stronger, the behavior intention is stronger, and the probability of behavior occurrence is greater (Ajzen, 1991). 


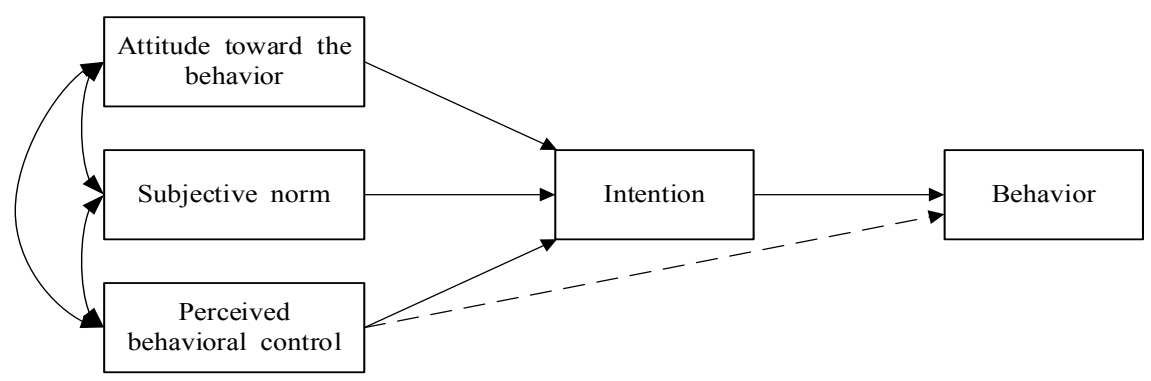

Figure 1. Theoretical model of planned behavior.

Judging from the existing literature, the theory of planned behavior is mainly used in the health field, with relatively few studies in the education field (Macfarlane \& Woolfson, 2013; Taylor, 2015). In addition, some researchers have used the theory of planned behavior to test the relationship between teachers' attitudes and behaviors towards SEBD children. The results of their research show that teachers' perception of principals' expectations is the only important factor that can predict teacher behavior, that is, subjective norms can predict Teacher behavior (Macfarlane \& Woolfson, 2013). At present, there are not many studies on the planning behavior theory in students' intention of enter to higher education. There are also foreign researchers who apply the theory of planned behavior to the study of educational background. For example, some researchers use the theory of planned behavior as the basis to explore and predict students' subject selection and media use intentions (Taylor, 2015). Now, some Chinese scholars have shown that the theory of planned behavior can be used to predict students' intention of enter to higher education. For example, Shi \& Liang (2018) are based on the theory of planned behavior, they found that due to the lack of positive behavior guidance of important others or groups, lack of social support, and insufficient sense of self-efficacy, secondary vocational students in underdeveloped areas in China have a weaker intention to enter higher education (Shi \& Liang, 2018). There are also researchers who study the intentions of secondary vocational students for further studies based on the theory of planned behavior. The results show that students' attitudes towards entering higher education have the greatest influence on their intention of entering higher education, followed by perceived behavioral control, while subjective norms have the least influence (Wang, 2020).

Through combing the existing literature, it can be seen that the theory of planned behavior, as a rational behavior theory that predicts individual behavior intentions, can effectively investigate the influence of individual behavior attitudes, subjective norms, and perceived behavioral control when an individual performs a certain behavior. In view of the low proportion of entering higher education in the underdeveloped areas of western China, this study is based on the theory of planned behavior to explore the influencing factors of secondary vocational students in the region and analyze the important predictive factors that affect students' intention of entering higher education. Therefore, this re- 
search proposes the following hypotheses:

Hypothesis 1: Secondary vocational students' attitude toward entering higher education, subjective norm, perceived behavioral control and their intention of entering higher education are positively correlated;

Hypothesis 2: Secondary vocational students' attitude toward enter to higher education, subjective norm, and perceived behavioral control positively predict students' intention of entering higher education.

\section{Methods}

\subsection{Participants}

The subjects of this research are Guangxi secondary vocational students located in western China. Select 8 secondary vocational schools in this province to collect data. 686 questionnaires were distributed online and a total of 686 questionnaires were collected. After excluding invalid questionnaires, a total of 606 valid questionnaires were obtained, and the effective recovery rate was $88.34 \%$. The subjects of the study included 319 males (52.6\%) and 287 females (47.4\%). The average age of students is 16.82 years (ranging from 14 to 23 years old, SD = 0.952). The majors studied by students include 7 categories, namely, finance and commerce, electronics and information, transportation, education and sports, tourism, civil engineering, and equipment manufacturing.

\subsection{Measurement}

This study uses the Intention of Entering Higher Education Influencing Factors Scale for Secondary Vocational Students compiled by Wang (2020). The scale includes attitude toward entering higher education, subjective norm, perceived behavioral control, and intention of entering higher education. Attitude toward entering higher education refers to students' views and attitudes towards entering higher education; Subjective norm is to understand the degree to which students are influenced by others in the process of entering a higher education; perceived behavioral control is to understand the judgment and evaluation of the opportunities, resources, time, and abilities that secondary vocational students have in the process of forming their admission behavior; Intention of entering higher education is to understand the choice tendency of secondary vocational students after graduation. The total scale reliability of the scale is 0.934 , among which the reliability of attitude toward entering higher education, subjective norm, performed behavioral control, and intention of entering higher education are 0.901 , $0.879,0.847$, and 0.834 , respectively. In this study, the total reliability of the scale is 0.953 , and the reliability of the attitude toward entering higher education, subjective norm, performed behavioral control, and intention of entering higher education subscales are $0.938,0.890,0.902$, and 0.910 , respectively.

\subsection{Data Analysis}

This study uses SPSS21.0 to process the data, mainly using descriptive statistics, 
independent sample $\mathrm{T}$ test, one-way analysis of variance, pearson correlation analysis, and stepwise regression analysis methods for data processing.

\section{Results}

\subsection{General Description}

Through descriptive statistics (as shown in Table 1), the educational backgrounds of the parents of secondary vocational students are mainly those of elementary and junior high schools, but the majority of them are junior high schools. It can be seen from the results of the research that most of the secondary vocational students have poor family economic conditions. Their monthly family income is basically below 5000 yuan, and even $51.5 \%$ of them are below 3000 yuan. Among the types of schools that students attend, most of them are enrolled in public schools, which accounts for $87.5 \%$ of the total number. For the entrance examination, $91.7 \%$ of students have the opportunity to take the entrance examination, which means that most of the students are qualified for entrance examination. The survey results also show that $72.1 \%$ of students have

Table 1. Basic information of the sample.

\begin{tabular}{|c|c|c|c|}
\hline Variable & Category & Frequency & $\%$ \\
\hline \multirow{4}{*}{ mother's degree } & elementary school and below & 220 & 36.3 \\
\hline & junior high school & 298 & 49.2 \\
\hline & high school & 75 & 12.4 \\
\hline & college degree and above & 13 & 2.1 \\
\hline \multirow{4}{*}{ father's degree } & elementary school and below & 162 & 26.7 \\
\hline & junior high school & 342 & 56.4 \\
\hline & high school & 85 & 14 \\
\hline & college degree and above & 17 & 2.8 \\
\hline \multirow{5}{*}{ family monthly income } & 3000 and below & 312 & 51.5 \\
\hline & $3000-5000$ & 229 & 37.8 \\
\hline & $5000-7000$ & 46 & 7.6 \\
\hline & $7000-9000$ & 10 & 1.7 \\
\hline & 9000 and above & 9 & 1.5 \\
\hline \multirow{2}{*}{ types of schools } & public & 530 & 87.5 \\
\hline & private & 76 & 12.5 \\
\hline \multirow{2}{*}{$\begin{array}{l}\text { have opportunities for entrance } \\
\text { examinations }\end{array}$} & yes & 556 & 91.7 \\
\hline & no & 50 & 8.3 \\
\hline \multirow{2}{*}{ guidance for further education } & yes & 437 & 72.1 \\
\hline & no & 169 & 27.9 \\
\hline \multirow{2}{*}{ intention of school type } & normal courses & 272 & 44.9 \\
\hline & short-cycle courses & 320 & 52.8 \\
\hline
\end{tabular}


received guidance for further studies from the school. For schools with the intention of entering higher education, $44.9 \%$ of students want to enter to normal courses, and $52.8 \%$ of students want to enter a higher vocational college (shortcycle courses).

\subsection{Difference Description}

The performance of secondary vocational students of different genders in each dimension is shown in Table 2. In this study, the independent sample $\mathrm{T}$ test method was used to test gender differences. From the significance, it can be seen that perceived behavioral control, intention of entering higher education, and attitude toward entering higher education show significant differences in different genders. The specific performance is that girls' perceived behavioral control, attitude toward entering higher education and intention of entering higher education are significantly higher than boys.

It can be seen from Table 3 that the $P$ values of students of different grades in the three dimensions of perceived behavioral control, attitude toward entering higher education, and intention of entering higher education are less than 0.05 . Therefore, students of different grades have significant differences in these three dimensions. Using the LSD method to conduct multiple post-comparisons (as shown in Table 4), There are significant differences between the students in the first grade and the second grade in the three dimensions of perceived behavioral control, attitude toward entering higher education, and intention of entering higher education. The specific performance is that the intention of entering higher education of the first grade students is higher, their attitude towards entering higher education is more positive, and their performance in perceived behavioral control is also better.

In this study, the average scores of students' academic performance are divided into five levels: $90-99,80-89,70-79,60-69$, and below 60, corresponding to excellent, good, medium, pass, and failed respectively. Using the

Table 2. Analysis of gender differences among different dimensions.

\begin{tabular}{ccccccc}
\hline Dimensions & Gender & $\mathrm{N}$ & $\mathrm{M}$ & $\mathrm{SD}$ & $\mathrm{T}$ & Sig \\
\hline \multirow{2}{*}{ PBC } & male & 319 & 3.607 & 0.841 & \multirow{2}{*}{ fe.636 } & 0.009 \\
& female & 287 & 3.775 & 0.711 & & \\
\hline \multirow{2}{*}{ SN } & male & 319 & 3.462 & 0.874 & & \\
& female & 287 & 3.493 & 0.663 & -0.488 & 0.626 \\
\multirow{2}{*}{ ATEHE } & male & 319 & 3.920 & 0.918 & & \\
& female & 287 & 4.328 & 0.684 & -6.158 & 0.000 \\
\multirow{2}{*}{ IEHE } & male & 319 & 3.893 & 0.982 & & \\
& female & 287 & 4.286 & 0.801 & -5.354 & 0.000 \\
\hline
\end{tabular}

Note: PBC: Perceived behavioral control; SN: Subjective norm; ATEHE: Attitude toward entering higher education; IEHE: Intention of entering higher education. 
Table 3. Analysis of the differences of dimensions in different grades.

\begin{tabular}{ccccccc}
\hline Dimensions & Grade & N & M & SD & F & Sig \\
\hline \multirow{2}{*}{ PBC } & senior 3 & 41 & 3.777 & 0.834 & & \\
& senior 2 & 218 & 3.826 & 0.779 & 6.541 & 0.002 \\
& senior 1 & 347 & 3.588 & 0.772 & & \\
SN & senior 3 & 41 & 3.640 & 0.742 & & \\
& senior 2 & 218 & 3.533 & 0.766 & 2.313 & 0.100 \\
& senior 1 & 347 & 3.422 & 0.791 & & \\
ATEHE & senior 3 & 41 & 4.134 & 0.688 & & \\
& senior 2 & 218 & 4.330 & 0.807 & 12.512 & 0.000 \\
& senior 1 & 347 & 3.974 & 0.849 & & \\
\hline \multirow{2}{*}{ IEHE } & senior 3 & 41 & 4.122 & 0.842 & & \\
& senior 2 & 218 & 4.310 & 0.842 & 11.869 & 0.000 \\
& senior 1 & 347 & 3.929 & 0.949 & & \\
\hline
\end{tabular}

Note: PBC: Perceived behavioral control; SN: Subjective norm; ATEHE: Attitude toward entering higher education; IEHE: Intention of entering higher education.

Table 4. Post-multiple comparative analysis of LSD in three dimensions in different grades.

\begin{tabular}{crrrrrr}
\hline \multirow{2}{*}{ Dimensions } & \multirow{2}{*}{ Grade } & SE & Sig & \multicolumn{2}{c}{$95 \%$ CI } \\
\cline { 6 - 7 } & & & & Lower & Upper \\
\hline PBC & senior 2 & senior 1 & 0.067 & 0.000 & 0.106 & 0.37 \\
ATEHE & senior 2 & senior 1 & 0.071 & 0.000 & 0.216 & 0.496 \\
IEHE & senior 2 & senior 1 & 0.078 & 0.000 & 0.227 & 0.534
\end{tabular}

Note: PBC: Perceived behavioral control; SN: Subjective norm; ATEHE: Attitude toward entering higher education; IEHE: Intention of entering higher education.

one-way analysis of variance method to test, it is found that there are significant differences in the perceived behavioral control, attitude toward entering higher education, and intention of entering higher education among students of different grades (as shown in Table 5). After further multiple comparative analysis of the LSD method (as shown in Table 6), in the dimension of perceived behavioral control, there is a significant difference between the students who have failed and the students who have pass and good grades. That is to say, the perceived behavioral control level of the students who failed the grade was significantly lower than that of the students who passed and the good grades. In the dimension of attitude towards entering higher education, the students who failed the grades were significantly lower than the students with excellent, good, medium, and passing grades, and the students with good grades were also significantly higher than those who passed the grades. In terms of intention to enter higher education, students with excellent, good, medium, and pass grades are significantly 
Table 5. Analysis of the difference of different academic performance levels in each dimension.

\begin{tabular}{|c|c|c|c|c|c|c|}
\hline Dimensions & Academic performance & $\mathrm{N}$ & M & $\mathrm{SD}$ & $\mathrm{F}$ & Sig \\
\hline \multirow{5}{*}{ PBC } & excellent & 41 & 3.753 & 1.103 & \multirow{5}{*}{2.536} & \multirow{5}{*}{0.039} \\
\hline & good & 116 & 3.819 & 0.742 & & \\
\hline & medium & 178 & 3.676 & 0.684 & & \\
\hline & pass & 159 & 3.714 & 0.714 & & \\
\hline & failed & 112 & 3.501 & 0.911 & & \\
\hline \multirow{5}{*}{ SN } & excellent & 41 & 3.417 & 1.062 & \multirow{5}{*}{0.882} & \multirow{5}{*}{0.474} \\
\hline & good & 116 & 3.569 & 0.727 & & \\
\hline & medium & 178 & 3.466 & 0.700 & & \\
\hline & pass & 159 & 3.501 & 0.754 & & \\
\hline & failed & 112 & 3.387 & 0.869 & & \\
\hline \multirow{5}{*}{ ATEHE } & excellent & 41 & 4.248 & 1.083 & \multirow{5}{*}{9.904} & \multirow{5}{*}{0.00} \\
\hline & good & 116 & 4.361 & 0.727 & & \\
\hline & medium & 178 & 4.182 & 0.782 & & \\
\hline & pass & 159 & 4.101 & 0.726 & & \\
\hline & failed & 112 & 3.716 & 0.954 & & \\
\hline \multirow{5}{*}{ IEHE } & excellent & 41 & 4.268 & 1.157 & \multirow{5}{*}{9.075} & \multirow{5}{*}{0.000} \\
\hline & good & 116 & 4.366 & 0.817 & & \\
\hline & medium & 178 & 4.112 & 0.814 & & \\
\hline & pass & 159 & 4.066 & 0.842 & & \\
\hline & failed & 112 & 3.679 & 1.059 & & \\
\hline
\end{tabular}

Note: PBC: Perceived behavioral control; SN: Subjective norm; ATEHE: Attitude toward entering higher education; IEHE: Intention of entering higher education.

Table 6. LSD post-multiple comparative analysis of different academic performance levels in three dimensions.

\begin{tabular}{ccccccc}
\hline \multirow{2}{*}{ Dimensions } & \multirow{2}{*}{ Academic performance } & SE & Sig & \multicolumn{2}{c}{$95 \%$ CI } \\
\cline { 6 - 7 } PBC & failed & good & 0.104 & 0.002 & -0.521 & -0.114 \\
& & pass & 0.096 & 0.028 & -0.402 & -0.024 \\
\hline \multirow{2}{*}{ ATEHE } & good & pass & 0.100 & 0.009 & 0.064 & 0.456 \\
& failed & excellent & 0.149 & 0.000 & -0.825 & -0.24 \\
& & good & 0.108 & 0.000 & -0.857 & -0.433 \\
& & medium & 0.098 & 0.000 & -0.659 & -0.273 \\
& & pass & 0.101 & 0.000 & -0.583 & -0.187 \\
\hline \multirow{3}{*}{ IEHE } & good & medium & 0.107 & 0.018 & 0.044 & 0.464 \\
& & pass & 0.110 & 0.006 & 0.085 & 0.516 \\
& & excellent & 0.164 & 0.000 & -0.911 & -0.268 \\
& & good & 0.119 & 0.000 & -0.921 & -0.454 \\
& & medium & 0.108 & 0.000 & -0.646 & -0.221 \\
& & pass & 0.111 & 0.000 & -0.605 & -0.17 \\
\hline
\end{tabular}

Note: PBC: Perceived behavioral control; SN: Subjective norm; ATEHE: Attitude toward entering higher education; IEHE: Intention of entering higher education. 
higher than those with failing grades, and students with good academic performance are also significantly higher than those with pass and medium grades.

\subsection{Correlation Description}

From Table 7, it can be seen that there is a significant positive correlation between the intention of entering higher education of secondary vocational students and perceived behavioral control, subjective norms and attitude toward entering higher education. The correlation coefficient between the intention to enter school and the perceived behavioral control was $0.643(P<0.01)$, which was a moderately positive correlation. The correlation coefficient between the intention of entering higher school and the subjective norm is $0.525(P<0.01)$, which is also a moderately positive correlation. There is a high degree of positive correlation between the intention of entering higher school and the attitude toward entering higher education, with a correlation coefficient of 0.78 ( $P$ $<0.01)$. It can be seen from the relevant analysis results that research hypothesis 1 is established. The results of the study also show that the intention of secondary vocational students to enter a higher school is most strongly influenced by the students' own attitude, followed by perceived behavioral control, and subjective norms have the weakest influence on students' intention to enter a higher school.

\subsection{Regression Analysis}

In order to get the most suitable regression equation, this study uses stepwise regression analysis to analyze the data. Perceived behavioral control, attitude toward entering higher education, and intention of entering higher education are included in the regression equation as independent variables (as shown in Table 8). In Model 1, the attitude toward higher education can explain $60.9 \%(\mathrm{~F}(1,604)=$ 939.611, $P=0.000$ ) of secondary vocational students' intention to enter higher education. The $\mathrm{R}$ square after adjustment still has an explanatory power of $60.8 \%$. The second one selected into the model is perceived behavioral control. The F change is $61.682(P=0.000)$, so this variable meets the criteria for selection (Qiu, 2013). It can be seen from the results that the amount of interpretation of perceived behavioral control on the intention of entering higher education is 3.6\%. In Model 2, the total explanation of the e attitude toward entering

Table 7. Correlation description of different dimensions.

\begin{tabular}{ccccccc}
\hline Dimensions & M & SD & PBC & SN & ATEHE & IEHE \\
\hline PBC & 3.686 & 0.786 & 1.000 & & & \\
SN & 3.477 & 0.781 & $0.748^{\star *}$ & 1.000 & & \\
ATEHE & 4.113 & 0.840 & $0.635^{\star *}$ & $0.592^{\star *}$ & 1.000 & \\
IEHE & 4.079 & 0.921 & $0.643^{\star *}$ & $0.525^{\star *}$ & $0.780^{\star *}$ & 1.000 \\
\hline
\end{tabular}

Note: ${ }^{* *}: P<0.01$; PBC: Perceived behavioral control; SN: Subjective norm; ATEHE: Attitude toward entering higher education; IEHE: Intention of entering higher education. 
Table 8. The results of the stepwise regression analysis of the three dimensions and IEHE

\begin{tabular}{|c|c|c|c|c|c|c|c|c|c|c|}
\hline \multirow[t]{2}{*}{ Model } & & \multicolumn{2}{|c|}{$\begin{array}{c}\text { Unstandardized } \\
\text { coefficient }\end{array}$} & \multirow{2}{*}{$\begin{array}{l}\text { Standardized } \\
\text { Coefficient B }\end{array}$} & \multirow[t]{2}{*}{$\mathrm{R}$} & \multirow[t]{2}{*}{ R square } & \multirow{2}{*}{$\begin{array}{l}\mathrm{R} \text { square after } \\
\text { adjustment }\end{array}$} & \multirow[t]{2}{*}{ F change } & \multirow[t]{2}{*}{ F } & \multirow[t]{2}{*}{ Sig } \\
\hline & & B & SE & & & & & & & \\
\hline \multirow{2}{*}{1} & (constant) & 0.561 & 0.117 & & \multirow{2}{*}{$0.780 \mathrm{~b}$} & \multirow{2}{*}{0.609} & \multirow{2}{*}{0.608} & \multirow{2}{*}{939.611} & \multirow{2}{*}{939.611} & \multirow{2}{*}{$0.000 \mathrm{~b}$} \\
\hline & ATEHE & 0.855 & 0.028 & 0.780 & & & & & & \\
\hline \multirow{3}{*}{2} & (constant) & 0.201 & 0.121 & & \multirow{3}{*}{$0.803 c$} & \multirow{3}{*}{0.645} & \multirow{3}{*}{0.644} & \multirow{3}{*}{61.682} & \multirow{3}{*}{547.846} & \multirow{3}{*}{$0.000 \mathrm{c}$} \\
\hline & ATEHE & 0.684 & 0.034 & 0.624 & & & & & & \\
\hline & $\mathrm{PBC}$ & 0.289 & 0.037 & 0.247 & & & & & & \\
\hline
\end{tabular}

Note: a (Dependent variable): IEHE; b (Predictor variable): ATEHE; c (Predictor variable): ATEHE, PBC.

higher education and the perceived behavioral control on the enrollment intention is $64.5 \%$, which is $64.4 \%$ after adjustment. This explanatory power is statistically significant $(\mathrm{F}(2,603)=547.846, \mathrm{P}=0.000)$. The explanatory quantity of subjective norms for the intention of entering higher education does not reach the significant level and is not included in the regression equation (Qiu, 2013). Therefore, hypothesis 2 only partially holds. The final regression equation is as follows.

\section{Discussion}

This research is based on the theory of planned behavior to study 686 students from many secondary vocational schools in the underdeveloped western regions of China. Use independent sample $\mathrm{T}$ test, stepwise regression analysis, one-way analysis of variance and other methods for data processing. This research reports the basic situation of secondary vocational students' intentions, attitudes, perceived behavioral control, and subjective norms. At the same time, the correlation and predictive analysis between these four different dimensions are also analyzed.

\subsection{There Are Significant Differences in Some Demographic Factors in the Different Dimensions}

In terms of the characteristics of demographic variables, secondary vocational students' intention to enter a higher education showed significant differences in gender, grade, and academic performance. Female students, second-year students, and secondary vocational students with high academic performance have stronger intentions for further studies. However, we do not believe that there is a clear difference in "male and female differentiation" in the advancement of secondary vocational students, and such gender differences are not universal. The main reason for this gender difference may be that the economic and social development in western China is generally backward, and the backward idea of prefer boys over girls is still rooted in most families. Especially in rural families, the treatment of male and female students differs greatly. In this reality, the 
educational resources and support that girls can obtain are far lower than that of boys. It is difficult for boys to arouse their thirst for knowledge and enthusiasm for struggle in such a comfortable environment, while girls have a passionate and strong intention to enter school because they want to change their destiny through education. Therefore, this gender difference has the cross effect of the social and environmental factors behind it, although it is not extensive. But this also warns us that we should pay attention to the fact that prefer boys over girls may still be a major barrier to education in underdeveloped areas.

Compared with gender, the difference in grades of secondary vocational students' attention of entering higher education is more realistic and reasonable. The data shows that students in the second grade of secondary vocational school have a stronger intention of entering higher education than the students in the first grade of secondary vocational school, and their attitude toward entering higher school is more positive and optimistic, and their performance in perceived behavioral control is also better. The rationality and practical significance of this data lie in the fact that second-year students can adapt to the school environment more after one year of study and life in a secondary vocational school. In addition, after a year of study and life in high school, the students in the second grade have a clearer understanding of the ways and methods to enter a higher school, and the students have a clearer plan for the future. Therefore, it is realistic and reasonable for the students in the second grade of high school to have a strong intention of entering higher education. In contrast, after the first-year students failed the brutal high school entrance examination, they went into secondary vocational studies with the feeling of being "losers" who were excluded by ordinary high schools. At this stage, students tend to give negative and excessively degrading negative behaviors and attitudes to self-evaluation. The changes of students in the first and second grades this year also reflect the adaptability of most secondary vocational students and the effectiveness of secondary vocational schools in guidance for further studies. This also further explains the importance and significance of school guidance and career education. Therefore, the sooner the school provides guidance of entering higher school and extensive career education for secondary vocational students, it will help students to clarify the prospects and trends of future employment, and help secondary vocational students to plan their careers and establish their goals for further studies as soon as possible.

On the other hand, there are also significant differences between the level of academic performance and the intention of secondary vocational students to enter higher education. Students with excellent, good, and pass academic performance are significantly higher than those with failed academic performance, and students with excellent academic performance are also significantly higher than those with other academic performance levels. Existing studies have shown that students' academic performance is affected by their own hopes and core self-evaluation (Griggs \& Crawford, 2017). This also explains the performance of 
students with excellent, good, and passed academic performance in their intention of entering higher school. This group of students will have higher selfexpectations, which is reflected in their intention to enter a higher school. For education units, schools, and parents, the most important thing is to work together to help students build up a sense of self-efficacy, carry out curriculum related to resilience education, and help students build good self-confidence and frustration. Only in this way can secondary vocational students understand themselves correctly and help them clarify their goals for further studies and future plans, so as to finally achieve the goal of improving the quality of labor and the quality of workers.

\subsection{The Important Influence of Predictors in the Theory of Planned Behavior on Students' Intention of Enter to Higher Education}

This study found that the secondary vocational students' attitude toward entering higher education, perceived behavioral control, and subjective norms in the planned behavior theoretical model are all positively correlated with their intention of entering higher education. This means that the more positive and optimistic secondary vocational students look at their admission behavior, the more they are able to face up to the difficulties in the process of admission, and the greater the influence of important others on their admission, the stronger their intentions for admission will be. Further analysis using stepwise regression analysis found that among these three dimensions (attitude toward entering higher education, perceived behavioral control, and subjective norms), the attitude toward entering higher education has the strongest interpretation of the intention of entering higher education. The specification does not enter the regression model. In other words, even if the student realizes that it is difficult to enter higher education, and his classmates and friends do not support his behavior. As long as students have positive and optimistic views and attitudes towards the behavior of entering higher education, students can largely eliminate the interference and influence of other factors on their intention to enter higher education.

To sum up, the personal internal factors of secondary vocational students are the main and direct factors that affect their intention to enter higher education, rather than external factors. Therefore, we must make it clear that increasing the proportion of secondary vocational schools and increasing the willingness of secondary vocational students should start from the direct factor of cultivating students' positive and optimistic emotions and attitudes for further studies.

\section{Suggestion}

\subsection{Expand the Proportion of Undergraduate Colleges Enrolling Secondary Vocational Students}

The survey results of this research show that 272 (44.9\%) students' intention to 
enter university are normal course, and 320 (52.8\%) students' intention to enter higher vocational colleges. Based on the current situation of secondary vocational students in the survey area of this research, the number of secondary vocational students entering normal course in 2020 was 2100 . In 2020, the total number of secondary vocational students promoted to higher vocational and normal course is 40,559 . The proportion of students entering short-cycle course and normal course differs greatly from the needs of students. Therefore, it is suggested to further expand the proportion of secondary vocational school students entering normal courses, so that more students can realize their university dreams. Through a more convenient and effective secondary vocational-higher education connection, ordinary high schools and vocational schools can be truly equal. On this basis, it is possible to improve the recognition and acceptance of secondary vocational education by the society, schools, parents, and students.

\subsection{Help Students Improve Their Adaptability in Study and Life}

In this study, it can be seen that the intention of students in the second grade of senior high school is significantly higher than that of the students in the first grade. To a certain extent, this reflects the results of the school's one-year education and teaching work for students, and also means that this year's training can make students more aware of future academic directions and goals, and treat the future more confidently. Vocational schools can help students improve their ability to adapt to their studies and life in secondary vocational schools as soon as possible, which will enable students to establish academic goals and directions for further studies earlier. Kant once said that "living without a goal is like sailing without a compass". Fast through the unadapted period of secondary vocational learning and establishing academic goals as early as possible can allow students to study purposefully, thereby increasing the rate of admission. Therefore, the training of first-year students in secondary vocational schools should focus on guiding students to adapt to the study and life of secondary vocational schools. In this way, students can adapt to the training and management of secondary vocational schools as soon as possible, so that students can invest more learning time and help students set learning goals.

\subsection{Enhance Students' Academic Self-Efficacy and Self-Evaluation}

The survey results show that the better the academic performance of secondary vocational students, the stronger their desire for entering higher education. On the dimension of intention to enter higher education, the average scores of the students with intermedium and passing test scores are also above the middle level, which indicates that the group with strong intention to enter higher education is not only secondary vocational students with excellent academic performance. Therefore, schools should attach importance to helping students to manage their studies, setting learning goals in stages, allowing students to experience the joy of learning and academic satisfaction in the process of completing each small 
learning goal, enhancing students' sense of learning and self-confidence, and strengthening students a sense of academic self-efficacy. At the same time, vocational schools should also carry out thematic education related to students' self-evaluation and self-expectations in a timely manner, encourage and guide students to make correct and positive self-evaluation, encourage students to establish positive learning goals, and help every student grow up healthily.

\subsection{Improve the Thematic Education, Guidance and Career Education for the Promotion of Students in Secondary Vocational Schools}

On one hand, the research results show that the three aspects of students' attitude toward the behavior, subjective norms and perceived behavioral control are significantly positively correlated with students' intention of entering higher education. Therefore, from the school level, schools should set up a series of educational activities related to the theme of entering higher education, including this promotion mobilization activity, the experience sharing activities of the students who have accepted, and the popularization of the knowledge of the parents. This makes the students, their parents and the students around the students pay attention to the problem of students entering higher education, thereby effectively improving the students' scoring level in the three aspects of their Attitude towards the behavior, Subjective norms and Perceived behavioral control, thereby enhancing students' intention to enter higher schools.

On the other hand, the school and teachers should pay attention to giving the students guidance on further education, help students understand the favorable policy and suitable channels for students' personal further education, and provide students with comprehensive college information and professional information so that students can be more clear about their choice and goals for further education. In addition, career education can help students improve their awareness of career planning. Vocational schools can help students understand the multiple choices they face at present and after graduation, such as further studies and employment, so as to arouse students' career awareness and make a good plan for their future careers.

\section{Acknowledgements}

The authors would like to thank the reviewers for their valuable comments on the manuscript.

\section{Funding}

This research was funded by Jiangsu Province University's Advantageous Discipline Construction Project, grant number "PAPD".

\section{Conflicts of Interest}

The authors declare no conflicts of interest regarding the publication of this paper. 


\section{References}

Ajzen, I. (1991). The Theory of Planned Behavior. Organizational Behavior and Human Decision Processes, 50, 179-217. https://doi.org/10.1016/0749-5978(91)90020-T

Armitage, C. J., \& Conner, M. (2001). Efficacy of the Theory of Planned Behaviour: A Meta-Analytic Review. British Journal of Social Psychology, 40, 471-499. https://doi.org/10.1348/014466601164939

Chen, S. H., \& Zhang L. X. (2017). Transformation and Upgrading of Vocational Education in the View of "Made in China 2025". Journal of Modern Education Management, 107-113. (in Chinese) https://www.cnki.net/kcms/doi/10.16697/j.cnki.xdjygl.2017.07.019.html

Griggs, S., \& Crawford, S. L. (2017). Hope, Core Self-Evaluations, Emotional Well-Being, Health-Risk Behaviors, and Academic Performance in University Freshmen. Journal of Psychosocial Nursing and Mental Health Services, 55, 33-42.

Li, Y. J., \& Gu, Y. (2017). Effective Transition of Secondary and Higher Vocational Education via Institution and Willingness. Journal of Hebei Normal University (Educational Science), 19, 56-61. (in Chinese) https://www.cnki.net/kcms/doi/10.13763/j.cnki.jhebnu.ese.2017.05.010.html

Lin, Y., Zhang, Z. Y., \& Yang, X. B. (2007). Applied Analysis on Criterion and Index System of Underdeveloped Region. Journal of Chongqing University, 12, 119-124. (in Chinese)

Liu, Y. K. (2021). Reality and Outlet of Rural Collective Economic Development in Underdeveloped Areas: From the Latecomer Theory Perspective. Journal of Zhejiang Gongshang University, 107-114. (in Chinese)

https://kns.cnki.net/kcms/detail/detail.aspx?doi=10.14134/j.cnki.cn33-1337/c.2021.04.010

Macfarlane, K., \& Woolfson, L. M. (2013). Teacher Attitudes and Behavior toward the Inclusion of Children with Social, Emotional and Behavioral Difficulties in Mainstream Schools: An Application of the Theory of Planned Behavior. Teaching \& Teacher Education, 29, 46-52. https://doi.org/10.1016/j.tate.2012.08.006

Qiu, Z. H. (2013). Quantitative Research and Statistical Analysis SPSS Data Analysis Paradigm Analysis (pp. 246-248). Chongqing University Press. (in Chinese)

Shi, H. B., \& Liang, Y. (2018). On the Promotion Path of the Connection of Secondary and Higher Vocational Education in Unerdeveloped Areas from the View of Students' Participation Intention. Journal of Vocational and Technical Education, 39, 48-52. (in Chinese)

Shi, W. P., \& Hao, T. C. (2017). Does It Need Secondary Vocational Education to Move towards Industry 4.0? Journal of Vocational Education (Late Edition), 71-72. (in Chinese) https://www.cnki.net/kcms/doi/10.13565/j.cnki.issn2095-4530.2017.05.027.html

Taylor, R. C. (2015). Using the Theory of Planned Behaviour to Understand Students' Subject Choices in Post-Compulsory Education. Research Papers in Education, 30, 214-231. https://doi.org/10.1080/02671522.2014.880732

Wang, Q. (2010). The Problems and Countermeasures of the Balanced Development of Vocational Education in China. Journal of Vocational Education, 70-73. (in Chinese)

Wang, Q. (2020). The Study on the Students' Intention to Advance to Higher Education in Secondary Vocational Schools Based on Theory of Planned Behavior. Master Thesis, Zhejiang Normal University. 